\title{
Transport of metal salts by zwitterionic ligands; simple but highly efficient salicylaldoxime extractants $\dagger$
}

\author{
Ross S. Forgan, James E. Davidson, Stuart G. Galbraith, David K. Henderson, \\ Simon Parsons, Peter A. Tasker* and Fraser J. White
}

Received (in Cambridge, UK) 22nd May 2008, Accepted 30th June 2008

First published as an Advance Article on the web 29th July 2008

DOI: $10.1039 / \mathrm{b808696f}$

\begin{abstract}
Attaching dialkylaminomethyl arms to commercial phenolic oxime copper extractants yields reagents which transport base metal salts very efficiently by forming neutral $1: 1$ or $1: 2$ complexes with zwitterionic forms of the ligands.
\end{abstract}

Ligands capable of binding both a metal cation and its attendant anion(s) show the potential to perform the unit operations of concentration and separation in extractive hydrometallurgical circuits. ${ }^{1,2}$ Substituted, salen-like salicylaldimines are effective metal salt extractants, with the cis arrangement of the cation binding groups forming a preorganised, doubly protonated anion binding site particularly suited to sulfate. ${ }^{3}$ However, the ease of acid hydrolysis of the imine functionality seen in related reagents ${ }^{4}$ may restrict their application in commercial operations which commonly use sulfuric acid concentrations of up to $150 \mathrm{~g} \mathrm{l}^{-1}$ to strip the metal. ${ }^{5}$ Conventional phenolic oxime cation exchange extractants account for approximately a fifth of the world's annual production of copper $^{6}$ and have half lives of over 2.5 years in kerosenes in contact with acid solutions. ${ }^{3}$ Consequently we have developed a new class of metal salt extractants based on the salicylaldoxime scaffold, and report here some remarkable benefits in using these reagents for metal recovery from chloride streams.

5-tert-Butyl-2-hydroxy-3-dihexylaminomethylbenzaldehyde oxime (L1) and 5-tert-butyl-2-hydroxy-3-piperidin-1-ylmethylbenzaldehyde oxime (L2) $\ddagger$ are salicylaldoximes bearing pendant dialkylaminomethyl arms, which are protonatable to form anion binding sites. As salicylaldoximes bind base metal cations in a trans arrangement ${ }^{7}$ these sites are expected to be well separated, forming a tritopic binding motif which may favour the transport of monoanions (Fig. 1).

The pendant dihexylaminomethyl arm of $\mathbf{L 1}$ imparts good solubility of both the ligand and its complexes in waterimmiscible solvents, allowing the extraction of copper and zinc salts to be studied (Table 1).

In both cases cation loading is greater from chloride media. Uptake is above $100 \%$, implying that the expected tritopic

School of Chemistry, University of Edinburgh, Edinburgh, UK

EH9 3JJ.E-mail: peter.tasker@ed.ac.uk; Fax: (+44) 131650 6453; Tel: $(+44) 1316504706$

$\dagger$ Electronic supplementary information (ESI) available: Ligand synthesis and solvent extraction. CCDC reference numbers 612042 , 660775 and 683051. For ESI and crystallographic data in CIF or other electronic format see DOI: $10.1039 / \mathrm{b} 808696 \mathrm{f}$

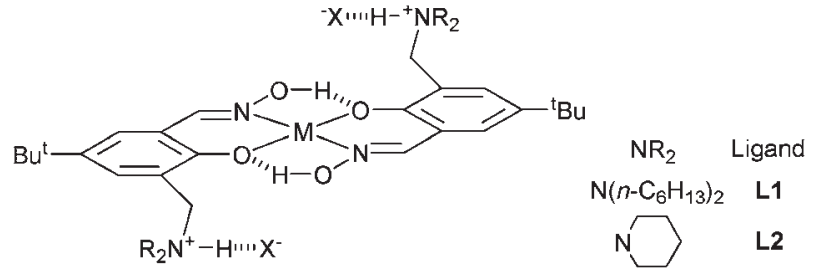

Fig. 1 Expected tritopic metal salt binding motif of $\mathbf{L 1}$ and $\mathbf{L 2}$.

binding motif (Fig. 1) does not apply and that metal salt binding involves a $1: 1$ stoichiometry:

$$
\mathbf{L}_{\mathrm{org}}+\mathrm{MCl}_{2} \rightleftharpoons\left[\mathrm{MLCl}_{2}\right]_{\mathrm{org}}
$$

This unexpectedly high efficiency of metal salt uptake greatly improves mass transfer over that shown by conventional phenolic oxime reagents and deviates from the expected binding model. Formation of $1: 1$ assemblies was confirmed by $\mathrm{X}$-ray structure determination of $\mathrm{Cu}^{\mathrm{II}}$ and $\mathrm{Zn}^{\mathrm{II}}$ chloride complexes of $\mathbf{L 2}$, the piperidinomethyl-substituted analogue of $\mathbf{L} \mathbf{1}$. $\left[\mathrm{Cu}(\mathbf{L} 2) \mathrm{Cl}_{2}\right] \S$ contains a zwitterionic form of the ligand with a phenolate oxygen atom and a piperidinium nitrogen atom (Fig. 2). This ensures that the overall assembly is charge neutral and allows the oximic $\mathrm{O}-\mathrm{H}$ and the piperidinium $\mathrm{N}-\mathrm{H}$ groups to form hydrogen bonds to chloride ions and the phenolate oxygen atom, which are in the inner coordination sphere of the $\mathrm{Cu}^{\mathrm{II}}$ ion. This intracomplex H-bonding provides an explanation for the favourable formation of the 1 : 1 complex and, together with the close $\mathrm{Cu} 1 \mathrm{~A} \cdots \mathrm{O} 1 \mathrm{~B}$ contacts, generates an assembly with polar functionality located centrally and a hydrophobic exterior.

Similar features are present in the zinc chloride complex, which has the dinuclear structure $\left[\mathrm{Zn}_{2}(\mathbf{L 2})_{2} \mathrm{Cl}_{4}\right] \S$ shown in Fig. 3. In this case the phenolate groups form similarly strong

Table 1 Cation and anion loadings $(\%)^{a}$ from aqueous $1 \mathrm{M}$ solutions of metal chlorides or sulfates by a $0.01 \mathrm{M}$ solution of $\mathbf{L} \mathbf{1}$ in $\mathrm{CHCl}_{3}$

\begin{tabular}{llllll}
\hline & \multicolumn{4}{l}{ \% Loading from aqueous media } \\
\cline { 2 - 3 } & Chloride & & Sulfate & \\
\cline { 2 - 3 } \cline { 5 - 6 } Metal & $\mathrm{M}$ & $\mathrm{Cl}$ & & $\mathrm{M}$ & $\mathrm{SO}_{4}$ \\
\hline $\mathrm{Cu}$ & 184 & 160 & 100 & 91 \\
$\mathrm{Zn}$ & 138 & 143 & 10 & 18
\end{tabular}

${ }^{a}$ Based on the formation of $1: 2$ metal salt to ligand ratios as in Fig. 1 . 


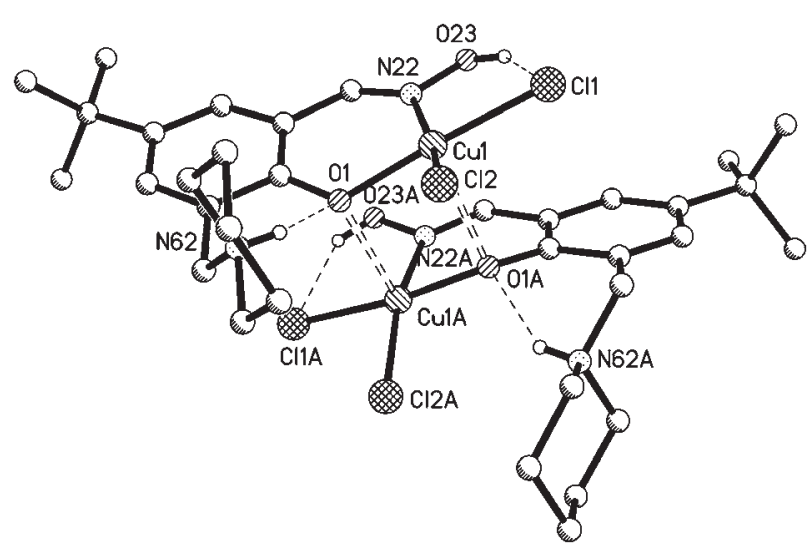

Fig. 2 Assembly of two $\left[\mathrm{Cu}(\mathbf{L} 2) \mathrm{Cl}_{2}\right]$ units in the solid state, with $\mathrm{Cu} 1 \mathrm{~A} \cdots \mathrm{O} 1 \mathrm{~B}=2.507(2) \AA$. Intracomplex H-bonding contacts; $\mathrm{N} 62 \cdots \mathrm{O} 1=2.754(3) \AA, \mathrm{N} 62 \cdots \mathrm{Cl} 2=3.560(3) \AA$ and $\mathrm{O} 23 \cdots \mathrm{Cl} 1=$ $2.925(3) \AA$.

bonds to both metal atoms, and the oximic $\mathrm{N}$ and two chloride ligands complete the distorted trigonal bipyramidal $\mathrm{NO}_{2} \mathrm{Cl}_{2}{ }^{3-}$ coordination sphere.

The favourable loadings of metal chlorides which are possible with the new type of extractant could underpin the development of very efficient processes for metal recovery from chloride feeds, for which a number of new leaching processes have recently been developed. Whilst many of these have the advantage of generating elemental sulfur rather than sulfate as a by-product from the processing of sulfidic ores (see for example the oxidative ferric chloride leaching of copper in Scheme 1) the very high chloride and proton activities of these feeds ${ }^{2}$ limits the efficiency of conventional phenolic oximes which operate in a $\mathrm{pH}$-dependent process (2):

$$
2 \mathbf{L}_{\text {org }}+\mathrm{Cu}^{\mathrm{II}} \rightleftharpoons\left[\mathrm{Cu}(\mathbf{L}-\mathrm{H})_{2}\right]_{\text {org }}+2 \mathrm{H}^{+}
$$

L1 has the advantage that it functions in a zwitterionic form, with no release of protons to the aqueous phase on extraction (eqn (1)) and therefore no $\mathrm{pH}$ adjustment is needed to achieve high loadings. Also, as a consequence of functioning in a zwitterionic form, it can be easily acid-stripped (Table 2) resulting in high mass transport efficiencies. $\|$

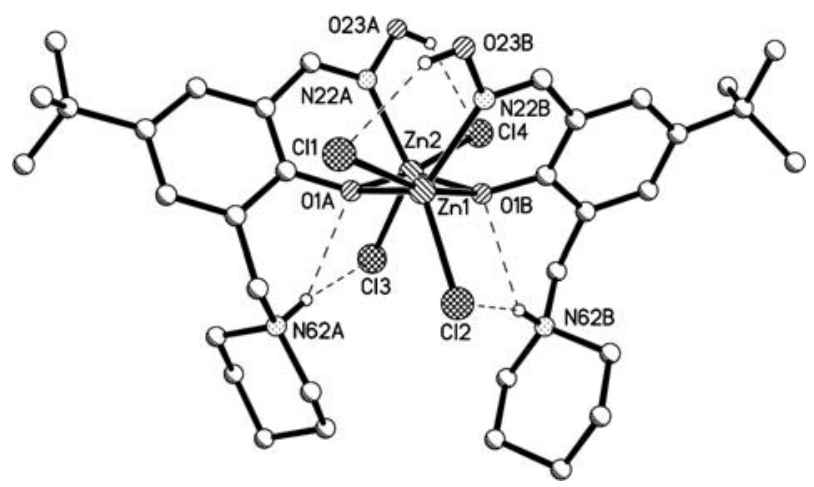

Fig. 3 The dinuclear complex $\left[\mathrm{Zn}_{2}(\mathbf{L} 2)_{2} \mathrm{Cl}_{4}\right], \mathrm{Zn} 1-\mathrm{O} 1 \mathrm{~A}=2.031(2) \AA$, $\mathrm{Zn} 1-\mathrm{O} 1 \mathrm{~B}=2.109(2) \AA, \mathrm{Zn} 2-\mathrm{O} 1 \mathrm{~A}=2.078(2) \AA$ and $\mathrm{Zn} 2-\mathrm{O} 1 \mathrm{~B}=$ 2.021(3) $\AA$. All chloride atoms form intramolecular H-bonds in the inner coordination spheres; $\mathrm{Cl} 1 \cdots \mathrm{O} 23 \mathrm{~B}=2.987(3) \AA \mathrm{A}, \mathrm{Cl} 2 \cdots \mathrm{N} 62 \mathrm{~B}=$ $3.446(2) \AA, \mathrm{Cl} 3 \cdots \mathrm{N} 62 \mathrm{~A}=3.379(3) \AA$ and $\mathrm{Cl} 4 \cdots \mathrm{O} 23 \mathrm{~A}=3.003(2) \AA$.

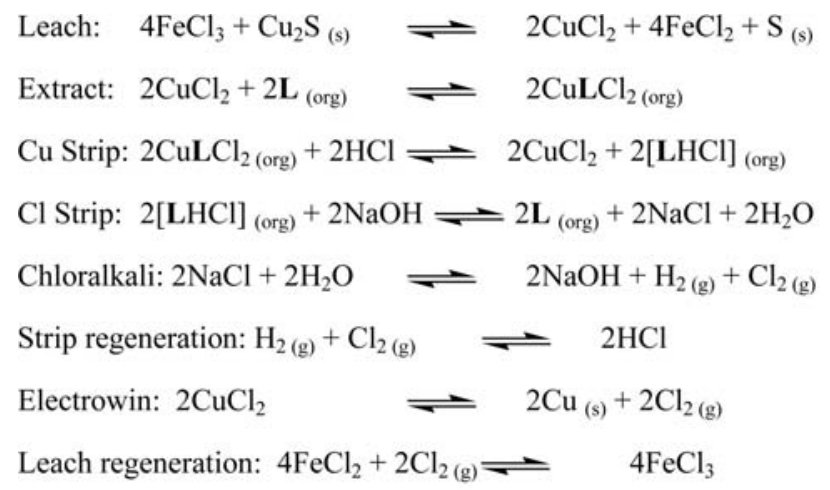

Scheme 1 Flowsheet for the processing of sulfidic copper ores, combining CUPREX $^{\mathrm{TM}}$ technology ${ }^{8}$ and the chloralkali process with a metal salt extractant such as $\mathbf{L 1}$.

As the chloride anions are extracted within the inner coordination sphere of the $\mathrm{Cu}^{\mathrm{II}}$ cation, high chloride concentration in the aqueous feed is expected to favour copper loading by L1. This is confirmed by solvent extraction (ESI $\dagger$ ) with maximum copper loading values of $\sim 180 \%$ observed with aqueous chloride concentrations above $0.8 \mathrm{M}$. These observations suggest L1 could operate as a conventional cation exchange reagent for copper extraction from chloride feeds to which conventional phenolic oxime reagents are not suited. ${ }^{4}$

Stability of L1 and L2 to acid hydrolysis under extraction conditions is imperative for commercial application. Both show little degradation when contacted with aqueous sulfate solutions of $\mathrm{pH}<1$, while a structurally related "salen" extractant hydrolysed completely (ESI $\dagger$ ). Most importantly in terms of material balances in metal recovery, the leaching and solvent extraction steps to effect concentration and separation could be coupled with well established technology, the CUPREX ${ }^{8}$ and chloralkali processes, to effect reduction to generate conductivity-grade copper and to regenerate all reagents used in the flowsheet (Scheme 1). In this case L1 operates as a metal salt reagent, and the overall material balance effectively involves the splitting of copper(I) sulfide ore into its component elements with the consumption of electrical power. Attempts to replicate the unexpected binding motif for $\mathrm{CuCl}_{2}$ and $\mathrm{ZnCl}_{2}$ with other salts were unsuccessful, and in most cases tritopic complexes of the type shown in

Table 2 Dependence of $\mathrm{Cu}$-stripping ${ }^{a}$ and molar transport efficiency ${ }^{b}$ on the concentration of the $\mathrm{HCl}$ strip solution

\begin{tabular}{lll}
\hline $\begin{array}{l}\% \mathrm{Cu} \text { in loaded } \\
\text { organic }\end{array}$ & $\begin{array}{l}\text { \% Cu in stripped organic } \\
\left([\mathrm{HCl}] / \mathrm{g}^{-1}\right)\end{array}$ & $\begin{array}{l}\text { Molar transport } \\
\text { efficiency }\end{array}$ \\
\hline 183 & $16(55)$ & 1.67 \\
185 & $17(110)$ & 1.68 \\
185 & $15(165)$ & 1.70 \\
184 & $8(220)$ & 1.76
\end{tabular}

${ }^{a}$ Based on formation of $1: 2 \mathrm{CuCl}_{2}$ to $\mathbf{L 1}$ complex as in Fig. 1. ${ }^{b}$ Moles of $\mathrm{Cu}$ transported by 2 moles of $\mathbf{L} \mathbf{1}$ after 1 load/strip cycle. 


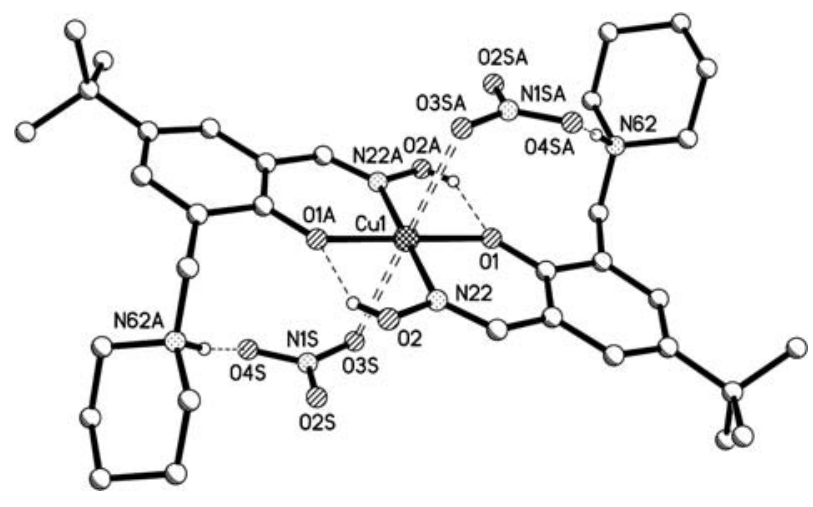

Fig. 4 The solid state structure of $\left[\mathrm{Cu}(\mathbf{L} 2)_{2}\left(\mathrm{NO}_{3}\right)_{2}\right]$, showing the interaction of the nitrate anion with the piperidinium $\mathrm{N}-\mathrm{H}$ group, $\mathrm{N} 62 \mathrm{~A} \cdots \mathrm{O} 4 \mathrm{~S}=2.842(2) \AA$, and the $\mathrm{Cu}^{\mathrm{II}}$ cation, $\mathrm{Cu} 1 \cdots \mathrm{O} 3 \mathrm{~S}=2.722(2) \AA$.

Fig. 1 were obtained. $\left[\mathrm{Cu}(\mathbf{L} 2)_{2}\left(\mathrm{NO}_{3}\right)_{2}\right] \S$ is typical, and shows the characteristic 14-membered pseudomacrocyclic H-bonding arrangement of bis-salicylaldoximato copper(II) species $^{7}$ (Fig. 4). Protonation of the piperidine moieties has generated two equivalent anion loading sites occupied by the nitrate anions, which are bound by a combination of electrostatic and $\mathrm{H}$-bond interactions. One oxygen atom of each nitrate anion is located above and below the $\mathrm{CuO}_{2} \mathrm{~N}_{2}$ coordination plane.

As the favoured formation of $1: 1 \mathbf{L}: \mathrm{MCl}_{2}$ assemblies with copper and zinc and their solubility in water-immiscible solvents appears to be very dependent on the new ligands addressing the chloride ions in the outer coordination sphere, it might be expected that $\mathbf{L} \mathbf{1}$ and its analogues will be selective for chloride over other anions. Preliminary results suggest that this is the case. Cation selectivity is also essential for commercial success, ${ }^{3}$ and detailed studies of these properties and other important features such as hydrolytic stability and solubility are in progress. ${ }^{9}$

The authors thank Mr Ronald M. Swart and Mr John Campbell at Cytec Industries Ltd. UK for useful discussions and the EPSRC for funding.

\section{Notes and references}

$\ddagger \mathbf{L 1}$ and $\mathbf{L 2}$ were prepared (ESI $\dagger$ ) in high yields and purity by oximation ${ }^{10}$ of their precursor aldehydes, which have been synthesised previously. ${ }^{11}$

$\S$ Synthesis of complexes: $\left[\mathrm{Cu}(\mathbf{L 2}) \mathrm{Cl}_{2}\right]$. $\mathbf{L 2}(29.0 \mathrm{mg}, 0.1 \mathrm{mmol})$ in $\mathrm{CHCl}_{3}(10 \mathrm{ml})$ and $\mathrm{CuCl}_{2}(1.34 \mathrm{~g}, 10 \mathrm{mmol})$ in water $(10 \mathrm{ml})$ were stirred together for $16 \mathrm{~h}$, the phases separated and the organic phase evaporated to give a purple solid (39.1 mg, 91\%). Crystals of $\left[\mathrm{Cu}(\mathbf{L} 2) \mathrm{Cl}_{2}\right]$ were grown by slow diffusion of $\mathrm{Et}_{2} \mathrm{O}$ into a $\mathrm{MeOH}$ solution. $\mathrm{C}_{17} \mathrm{H}_{26} \mathrm{Cl}_{2} \mathrm{CuN}_{2} \mathrm{O}_{2}, M_{\mathrm{r}}=424.85$, orthorhombic, space group, Pbcn, $a=16.542$ (2), $b=24.736$ (3), $c=10.4427$ (13) ,
$V=4272.9$ (9) $\AA, Z=6, T=150$ (2) $\mathrm{K}, 27848$ reflections collected, 4372 independent reflections $[R($ int $)=0.0749], R(F)=0.0545, \mathrm{w} R_{2}=$ 0.1319, CCDC 612042 (Found: C, 47.4; H, 6.4; N, 5.8. $\mathrm{C}_{17} \mathrm{H}_{26} \mathrm{Cl}_{2} \mathrm{CuN}_{2} \mathrm{O}_{2} \cdot \mathrm{CH}_{3} \mathrm{OH}$ requires $\left.\mathrm{C}, 47.3 ; \mathrm{H}, 6.6 ; \mathrm{N}, 6.1 \%\right)$. MS (FAB, NOBA) $m / z 390\left([\mathrm{M}-\mathrm{Cl}]^{+} 90 \%\right.$ ).

$\left[\mathrm{Zn}_{2}(\mathbf{L 2})_{2} \mathrm{Cl}_{4}\right]$. $\mathbf{L 2}(29.0 \mathrm{mg}, 0.1 \mathrm{mmol})$ in $\mathrm{CHCl}_{3}(10 \mathrm{ml})$ and $\mathrm{ZnCl}_{2}$ $(1.36 \mathrm{~g}, 10 \mathrm{mmol})$ in water $(10 \mathrm{ml})$ were stirred together for $16 \mathrm{~h}$, the phases separated and the organic phase slowly evaporated to give colourless crystals of $\left[\mathrm{Zn}_{2}(\mathbf{L 2})_{2} \mathrm{Cl}_{4}\right] \cdot 4 \mathrm{CHCl}_{3} \cdot \mathrm{C}_{34} \mathrm{H}_{52} \mathrm{~N}_{4} \mathrm{O}_{4} \mathrm{Zn}_{2} \cdot 4 \mathrm{CHCl}_{3}$, $M_{\mathrm{r}}=1330.81$, triclinic, space group, $P \overline{1}, a=14.1922(16), b=15.2573$ (17), $c=15.8100$ (17) $\AA, \alpha=90.166$ (2), $\beta=107.680$ (2), $\gamma=117.492$ $(2)^{\circ}, V=2851.6(5) \AA, Z=2, T=150$ (2) K, 25571 reflections collected, 13277 independent reflections $[R($ int $)=0.0195], R(F)=$ $0.045, \mathrm{w} R_{2}=0.1165, \mathrm{CSD} 660775$. The crystals were sensitive to solvent loss, and after exposure to air gave an off white solid which analysed as $\left[\mathrm{Zn}_{2}(\mathbf{L 2})_{2} \mathrm{Cl}_{4}\right] \cdot 2 \mathrm{CHCl}_{3}(13.1 \mathrm{mg}, 24 \%$ ) (Found: C, 39.9; $\mathrm{H}$, 5.1; N, 5.3. $\mathrm{C}_{34} \mathrm{H}_{52} \mathrm{Cl}_{4} \mathrm{~N}_{4} \mathrm{O}_{4} \mathrm{Zn}_{2} \cdot 2 \mathrm{CHCl}_{3}$ requires $\mathrm{C}, 39.6 ; \mathrm{H}, 5.0 ; \mathrm{N}$, $5.1 \%)$. MS (FAB, NOBA) $m / z 818\left([\mathrm{M}-\mathrm{Cl}]^{+} 25 \%\right) 781\left([\mathrm{M}-2 \mathrm{Cl}]^{+}\right.$ $74 \%)$.

$\left[\mathrm{Cu}(\mathbf{L} 2)_{2}\left(\mathrm{NO}_{3}\right)_{2}\right] . \mathrm{Cu}\left(\mathrm{NO}_{3}\right)_{2} \cdot 3 \mathrm{H}_{2} \mathrm{O}(23.3 \mathrm{mg}, 0.096 \mathrm{mmol})$ and $\mathbf{L 2}$ $(52.0 \mathrm{mg}, 0.179 \mathrm{mmol})$ were mixed in methanol $(20 \mathrm{ml})$ for $16 \mathrm{~h}$ and the solvent removed in vacuo to give a brown solid (71.8 $\mathrm{mg}, 99 \%)$. Crystals suitable for analysis by X-ray diffraction were grown by diffusion of diethyl ether into a methanol solution. $\mathrm{C}_{34} \mathrm{H}_{52} \mathrm{CuN}_{6} \mathrm{O}_{10}$, $M_{\mathrm{r}}=768.37$, monoclinic, space group, $P 2_{1} / n, a=11.8940$ (6), $b=$ 11.1620 (6) $c=14.8410$ (7) $\AA, \beta=112.682(3)^{\circ}, V=1817.92(16) \AA^{3}, Z$ $=2, T=150$ (2) K, 29119 reflections collected, 5192 independent reflections $[R(\mathrm{int})=0.049], R(F)=0.0409, w R_{2}=0.1119, \mathrm{CSD} 683051$ (Found: $\mathrm{C}, 53.6 ; \mathrm{H}, 6.9 ; \mathrm{N}, 10.3 . \mathrm{C}_{34} \mathrm{H}_{52} \mathrm{CuN}_{6} \mathrm{O}_{10} \cdot 0.5 \mathrm{C}_{4} \mathrm{H}_{10} \mathrm{O}$ requires C, 53.7; H, 7.1; N, 10.4\%). MS (FAB, NOBA) $m / z 707\left(\left[\mathrm{M}-\mathrm{NO}_{3}{ }^{+}\right]\right.$, $18 \%)$.

- 16 papers discussing chloride hydrometallurgy were presented at the recent 6th Copper/Cobre Conference, Toronto, August 2007, proceedings available at www.metsoc.org

$\|$ The mass of copper transported by $1 \mathrm{~kg}$ of ligand. ${ }^{5}$ Under the conditions in Table 2, L1 has an observed mass transport efficiency of $143 \mathrm{~g} \mathrm{~kg}^{-1}$ per cycle when stripped with $220 \mathrm{~g}^{-1} \mathrm{HCl}, c f$. a theoretical maximum of $121 \mathrm{~g} \mathrm{~kg}^{-1}$ calculated for the commercial reagent P50 (5-nonyl-2-hydroxybenzaldehyde oxime).

1 S. G. Galbraith and P. A. Tasker, Supramol. Chem., 2005, 17, 191-207.

2 P. A. Tasker, P. G. Plieger and L. C. West, Comprehensive Coordination Chemistry II, Elsevier, Amsterdam, 2004, vol. 9, pp. 759-808.

3 P. A. Tasker, C. C. Tong and A. N. Westra, Coord. Chem. Rev., 2007, 251, 1868, and references within.

4 N. Akkus, J. C. Campbell, J. Davidson, D. K. Henderson, H. A. Miller, A. Parkin, S. Parsons, P. G. Plieger, R. M. Swart, P. A. Tasker and L. C. West, Dalton Trans., 2003, 1932-1940.

5 J. Szymanowksi, Hydroxyoximes and Copper Hydrometallurgy, CRC Press, London, 1993.

6 P. J. Mackey, CIM Magazine, 2007, 2, 35-42.

7 A. G. Smith, P. A. Tasker and D. J. White, Coord. Chem. Rev., 2003, 241, 61-85.

8 R. F. Dalton, A. Burgess, R. Price and E. Hermana, Proc. Metall., 1992, 7B, 1145, and references within.

9 R. S. Forgan, D. K. Henderson and P. A. Tasker, UK Pat., P14523GB, 2006.

10 D. Stepniak-Biniakiewicz, Pol. J. Chem., 1980, 54, 1567-1571.

11 R. A. Coxall, L. F. Lindoy, H. A. Miller, A. Parkin, S. Parsons, P. A. Tasker and D. J. White, Dalton Trans., 2003, 55-64. 